\title{
Study on the Production Factors in the Process of Production and Properties of Fly Ash-Based Coarse Aggregates
}

\author{
K. N. Shivaprasad $\mathbb{I D}^{1}$ and Bibhuti Bhusan Das $\mathbb{1 D}^{2}$ \\ ${ }^{1}$ Department of Civil Engineering, JSS Science and Technology University, Mysuru 570006, India \\ ${ }^{2}$ Department of Civil Engineering, National Institute of Technology Karnataka, Surathkal, Mangalore 575025, India
}

Correspondence should be addressed to K. N. Shivaprasad; shivaprasad.god@gmail.com

Received 19 April 2021; Revised 30 July 2021; Accepted 19 August 2021; Published 2 September 2021

Academic Editor: Eleftherios K. Anastasiou

Copyright (C 2021 K. N. Shivaprasad and Bibhuti Bhusan Das. This is an open access article distributed under the Creative Commons Attribution License, which permits unrestricted use, distribution, and reproduction in any medium, provided the original work is properly cited.

\begin{abstract}
An optimization study was carried out for the sustainable production of coarse aggregates from fly ash and alkaline solution, considering the combined effect of alkaline solution and production process. The trial mixes during the process of producing the artificial aggregates were designed through Taguchi's experimental design method. The combined effect of alkaline solution (geopolymerisation) and production process (pelletization factors) along with engineering properties of the produced coarse aggregates was evaluated using response indices at different curing ages. Furthermore, the influence of each individual factor of geopolymerisation and pelletization on the engineering properties was determined through grey relational analysis to identify the most influencing factors in the production of coarse aggregates. The results obtained from grey relational analysis indicate that the properties of produced aggregates are governed mostly by geopolymerisation. It is also observed that water content of $20 \%$ by mass of fly ash is found to be essential for the suitable production of coarse aggregates and factors such as $\mathrm{Na}_{2} \mathrm{O}$ content and curing regime improved the engineering properties.
\end{abstract}

\section{Introduction}

The statistic depicts global concrete production is approximately 5.3 billion cubic meters per year [1]. Typically, ordinary concrete contains about $70-80 \%$ aggregate, $12 \%$ cement, and $8 \%$ mixing water by mass [2]. On the other hand, the use of aggregates in the construction of aggregates is enormous. In the year 2019, global demand for construction aggregates was more than 51.7 billion tonnes, which is estimated to grow $5.2 \%$ annually. In India alone, it is predicted that consumption of aggregates is more than 5 billion metric tonnes in the year 2020 [3]. At present, the consumption rate of natural aggregates in global level has reached an alarming level. Hence, there is a necessity of producing an alternative and sustainable material which could replace the natural aggregates in concrete.

Many researchers have reported on the aggregates production using fly ash with suitable binding materials through artificial process [4]. In the production process, it is noted that different techniques are available such as agglomeration, expansion (bloating), pressing and crushing, etc., [4-6]. However, it is observed that the pelletization process is well developed agglomeration technique for producing artificial aggregates [4, 7-9]. However, the adoption of pelletization process in producing the artificial aggregates is still not being adopted widely by the construction industry and hence the production cost of artificial aggregates is found to be high as compared to the cost of natural aggregates.

For artificial fly ash aggregates it has been reported that production and properties of the aggregates mainly depend on the raw materials, size of the particles in the raw materials, type of binder, specific surface area, the wettability of particles, and production process involved [4, 9-14]. However, researchers reported that the engineering properties of produced fly ash aggregates are mainly influenced by the type and composition of binder used in the production process along with the dosage of the binder [12-14]. 
From the literature it is to be noted that the production process can be controlled in a better way with a disc type pelletizer as compared to other types of pelletizers such as drum or cone pelletizers $[4,11]$. Furthermore, it is reported by the researchers that, in the pelletization process, different factors such as water content during pelletization, the angle of pelletizing disc, speed of pelletizing disc, and duration of the pelletization are the most influencing factors that affect the production process of aggregates $[4,11,12]$. The produced aggregates are subjected to different hardening methods such as sintering, normal water curing, cold bonding, steam curing, and autoclaving [4, 8, 10, 12-14].

The alkali activator solution, which acts as an activator in the geopolymerisation process, plays an important role in the surface hydrolysis of the raw material particles [15]. The alkaline solution with different types [15-19], concentrations [16-24], raw material to solution ratio [17, 25-27], and curing regime $[15,23,24,27,28]$ has a significant influence in the geopolymerisation process. However, there are a limited number of studies reported in the literature on the utilization of alkaline solutions for the production of artificial fly ash aggregates, whereas the factors responsible for fly ash aggregates production through pelletization process, combined with the factors of geopolymerisation, are very much essential to understand the efficient and effective production.

To investigate the combined effect of geopolymerisation and pelletization factors on the properties of artificial fly ash aggregates, an experimental study is very much essential which could be carried out with the help of design of experiments. Various optimization techniques are available such as factorial designs [11, 29-33], central composites [34-36], response surface methodology [11, 35, 36], and Taguchi method [11, 37, 38]. Taguchi's experimental design method is one of the best optimization methods defined by Genichi Taguchi which allows experimental trial runs to a small number and also to identify the influence of factors selected [11, 29]. Considering all the factors mentioned above, this experimental investigation was carried out to determine the combined effect of geopolymerisation and pelletization factors in the sustainable production of artificial aggregates using Taguchi's experimental design method followed by grey relational analysis.

1.1. Significance of the Study. The natural aggregates consumption is increasing rapidly because of the faster rate of infrastructure development worldwide. However, the mining of natural aggregates is creating a serious environmental imbalance. In the present situation, the challenge before the world is to have innovative and less carbon footprint materials for the construction industry. Hence, there is a need for an alternate material that can substitute the natural aggregate. Using artificial methods to produce substitute materials from industrial waste or byproducts will solve the disposal problem and at the same time, it is going to save natural resources. The use of artificially produced fly ash aggregate will gain significant importance for infrastructure development which can replace the naturally available materials.
The production of the artificial aggregates is having different methods as per requirements or the end use in the products, whereas many researchers reported on the process with different raw materials as well as the different binders for the production of artificial aggregates. The present study is concentrated on the production process by pelletization technique and alkaline solution content and on characteristics of produced coarse aggregate simultaneously.

\section{Materials and Methodology}

2.1. Materials. Locally available fly ash was used in the production of artificial fly ash aggregate. The fly ash had a specific gravity of 2.20 and a specific surface area of $260.30 \mathrm{~m}^{2} / \mathrm{kg}$. The chemical compositions are presented in Table 1 and the particle size distribution of fly ash analysed in the laboratory is presented in Figure 1. As per IS 3812 (Part 1) 2013 classification [39], fly ash has been classified as class $F$ type. The laboratory grade sodium silicate solution $\left(\mathrm{Na}_{2} \mathrm{SiO}_{3}\right)$ with alkali ratio $\left(\mathrm{SiO}_{2} / \mathrm{Na}_{2} \mathrm{O}\right)$ of $3.3\left(8.0 \% \mathrm{Na}_{2} \mathrm{O}\right.$, $26.5 \% \mathrm{SiO}_{2}, 65.5 \% \mathrm{H}_{2} \mathrm{O}$ by mass) and sodium hydroxide $(\mathrm{NaOH})$ flakes of $98 \%$ purity were used to prepare the alkaline solution.

2.2. Experimental Programme. The production of artificial aggregates is significantly affected by several factors such as type of alkali content and its dosage, raw material and its composition, and also the process of pelletization. In the present investigation, the raw material is fly ash and alkaline solution. To study the relative influence of several factors in the production process and aggregates properties, the following experimental programme was carried out.

The most influencing factors related to alkali content in geopolymerisation process and the factors related to geopolymerisation were identified as $\mathrm{Na}_{2} \mathrm{O}$ content, $\mathrm{SiO}_{2} / \mathrm{Na}_{2} \mathrm{O}$ ratio, water content, and curing methods [22-24, 26]. An increase of $\mathrm{Na}_{2} \mathrm{O}$ content and $\mathrm{SiO}_{2} / \mathrm{Na}_{2} \mathrm{O}$ ratio in alkaline solution will lead to higher level of binding property in the geopolymer [22-26]. The initial trial mixes were carried out with different composition of $\mathrm{Na}_{2} \mathrm{O}$ content from $3 \%$ to $7 \%$ (percentage of the mass of fly ash), water content from $18 \%$ to $22 \%$ (percentage of the mass of fly ash), and $\mathrm{SiO}_{2} / \mathrm{Na}_{2} \mathrm{O}$ ratio from 0.3 to 0.5 . This alkaline solution was then sprayed to the pelletization disc. It was observed that, with increase in $\mathrm{Na}_{2} \mathrm{O}$ content (from 3 to $7 \%$ ) and $\mathrm{SiO}_{2} / \mathrm{Na}_{2} \mathrm{O}$ ratio (from 0.3 to 0.5$)$ with constant water content $(21 \%)$, the alkaline solution was found to be highly viscous. This can be attributed to high content of solids in the solution $[19,40]$. Hence, in the present study alkaline solution composition is restricted to 4 to $6 \%$ of $\mathrm{Na}_{2} \mathrm{O}$ content along with the varying $\mathrm{SiO}_{2} /$ $\mathrm{Na}_{2} \mathrm{O}$ ratio from 0.3 to 0.5 and water content from $19 \%$ to $21 \%$.

Furthermore, factors related to pelletization process such as the angle of pelletizing disc, speed of pelletizing disc, water content, and duration of the pelletization were identified $[4,7,11]$. The angle and speed of pelletizing disc were varied from $35^{\circ}$ to $55^{\circ}$ with every $10^{\circ}$ interval and 30 to $50 \mathrm{RPM}$ with every 10 RPM interval, respectively. It is also observed from 
TABle 1: Chemical compositions of fly ash.

\begin{tabular}{lc}
\hline Chemical constituents & $(\%)$ \\
\hline $\mathrm{SiO}_{2}$ & 60.65 \\
$\mathrm{Al}_{2} \mathrm{O}_{3}$ & 28.62 \\
$\mathrm{Fe}_{2} \mathrm{O}_{3}$ & 3.95 \\
$\mathrm{MgO}$ & 1.84 \\
$\mathrm{CaO}$ & 1.70 \\
$\mathrm{SO}_{3}$ & 1.26 \\
$\mathrm{Na}_{2} \mathrm{O}$ & 1.11 \\
$\mathrm{~K}_{2} \mathrm{O}$ & 0.11 \\
$\mathrm{LOI}$ & 2.6 \\
\hline
\end{tabular}

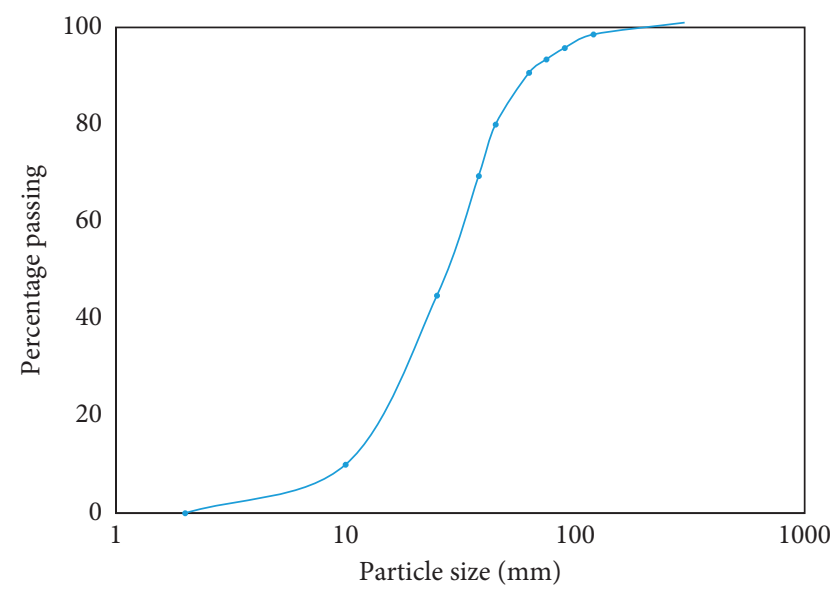

Figure 1: Particle size distribution of fly ash.

the literature, for the formation of pellets, a minimum of 10 to 15 minutes is needed [7] and 12 to 18 minutes were selected with an interval variation of 3 minutes in the present study.

Although water content is a factor where both geopolymerisation and pelletization are getting affected, in the present study it was restricted; 19 to $21 \%$ of water content (\% is with respect to mass of fly ash) was selected based on the previous study [41]. The water added in the preparation of sodium hydroxide solution and water present in the sodium silicate solution together reference as the water content in the alkaline solution.

After the production of aggregates, it is subjected to different curing conditions as follows: (i) curing at ambient temperature $\left(28 \pm 2^{\circ} \mathrm{C}\right)$, (ii) heat curing at $80^{\circ} \mathrm{C}$ for 24 hours $[15,23,24,27,42]$, and (iii) solution curing for 30 minutes [10] which will improve the properties of aggregates.

The objective of the present study is concerned with the investigation on the effect of geopolymerisation factors and pelletization factors as a combined factor in the aggregates production using fly ash as a raw material with alkali solution. To optimize the mixtures of fly ash and alkali solution in the production of artificial aggregates and to evaluate the interaction with the study parameters in the production and engineering properties of produced aggregates, the following design of experiments was used.
2.3. Design of Experiments with Taguchi's Orthogonal Array. Experimental design was carried out using Taguchi's orthogonal array. This orthogonal array was identified based on the factors and the levels which influence the most as described in the previous section and the same is presented in Table 2. In this phase the pelletization factors are allied with geopolymerisation factors and were investigated as the combined effect. The same was carried out with L27 $\left(3^{7}\right)$ Taguchi orthogonal array to study the engineering properties of the artificial aggregates. The essential variables for each experimental trial run are labelled from TMC 1 to TMC 27 and they are presented in Table 3.

In the second phase, the response index for individual factor was analysed with the help of Minitab software to evaluate the response indices for all the selected factors from the experimental test results. Further, grey relational analysis of a statistical approach was analysed to understand the effect of combined factors from their responses all together in the production of sustainable aggregates.

2.4. Alkaline Solution Preparation. The required quantity of sodium hydroxide $(\mathrm{NaOH})$ flakes was dissolved in normal tap water to prepare $\mathrm{NaOH}$ solution. The alkaline solution was prepared by mixing both $\mathrm{NaOH}$ solution and $\mathrm{Na}_{2} \mathrm{SiO}_{3}$ solution such that required proportions of $\mathrm{Na}_{2} \mathrm{O}$ content (\%), water content (\%), and $\mathrm{SiO}_{2} / \mathrm{Na}_{2} \mathrm{O}$ ratio are maintained as per each trial mix provided in Table 3 . With required proportion as specified in Table 3, alkaline solution is prepared and preserved in a closed container and allowed to cool, before using it in the production process.

2.5. Sustainable Aggregates Production. A laboratory scale disc pelletizer was used in this study $[41,42]$. Pelletization was carried out in the following steps:

(i) The required proportion of alkaline solution was prepared

(ii) The necessary adjustment was made to the pelletizer

(iii) Weighed fly ash was transferred to the pelletizing disc

(iv) Required alkali solution was sprayed to the disc pelletizer directly within first three minutes during the pelletization process

2.6. Curing of Aggregates. In the present investigation artificially produced fly ash (APFA) aggregates were subjected to different curing conditions as per experimental programme and the details of each curing condition are as follows:

Ambient curing (A): the APFA aggregates through the pelletization process are kept at a temperature of $28 \pm 2^{\circ} \mathrm{C}$ and relative humidity of $80 \%$ and were characterised at 14,28 , and 56 days.

Heat curing $(\mathrm{H})$ : the APFA aggregates through the pelletization process are allowed to set for 24 hours in ambient temperature conditions. After that, fly ash aggregates are subjected to a temperature of $80^{\circ} \mathrm{C}$ for 24 
TABLE 2: Different individual factors and their values considered in the study.

\begin{tabular}{lccc}
\hline Factors & L1 & L2 & \\
\hline $\mathrm{Na}_{2} \mathrm{O}$ content (\%) & 4 & 5 & L3 \\
$\mathrm{SiO}_{2} / \mathrm{Na}_{2} \mathrm{O}$ ratio & 0.3 & 0.4 & \\
Water content (\%) & 19 & 20 & 0.5 \\
Speed of pelletizing disc (RPM) & 30 & 40 & 21 \\
Angle of pelletizing disc ( $\left.{ }^{\circ}\right)$ & 35 & 45 & 50 \\
Duration of pelletization (minutes) & 12 & 15 & 55 \\
Curing regime & $\mathrm{A}$ & $\mathrm{H}$ & 18 \\
\hline
\end{tabular}

L: level; A: ambient temperature; H: heat cured; S: solution cured.

TABLE 3: Combined factors and values used in the production trial runs.

\begin{tabular}{|c|c|c|c|c|c|c|c|}
\hline \multirow{2}{*}{$\begin{array}{l}\text { Trial } \\
\text { runs }\end{array}$} & \multicolumn{7}{|c|}{ Factors } \\
\hline & $\begin{array}{c}\mathrm{Na}_{2} \mathrm{O} \\
\text { content }\end{array}$ & $\begin{array}{l}\mathrm{SiO}_{2} / \mathrm{Na}_{2} \mathrm{O} \\
\text { ratio }\end{array}$ & $\begin{array}{l}\text { Water } \\
\text { content }\end{array}$ & $\begin{array}{l}\text { Speed of pelletizing } \\
\text { disc }\end{array}$ & $\begin{array}{l}\text { Angle of pelletizing } \\
\text { disc }\end{array}$ & $\begin{array}{l}\text { Duration of } \\
\text { pelletization }\end{array}$ & $\begin{array}{l}\text { Curing } \\
\text { regime }\end{array}$ \\
\hline TMC 1 & 4 & 0.3 & 19 & 30 & 35 & 12 & $\mathrm{~A}$ \\
\hline TMC 2 & 4 & 0.3 & 19 & 30 & 45 & 15 & $\mathrm{H}$ \\
\hline TMC 3 & 4 & 0.3 & 19 & 30 & 55 & 18 & $S$ \\
\hline TMC 4 & 4 & 0.4 & 20 & 40 & 35 & 12 & $\mathrm{~A}$ \\
\hline TMC 5 & 4 & 0.4 & 20 & 40 & 45 & 15 & $\mathrm{H}$ \\
\hline TMC 6 & 4 & 0.4 & 20 & 40 & 55 & 18 & S \\
\hline TMC 7 & 4 & 0.5 & 21 & 50 & 35 & 12 & $\mathrm{~A}$ \\
\hline TMC 8 & 4 & 0.5 & 21 & 50 & 45 & 15 & $\mathrm{H}$ \\
\hline TMC 9 & 4 & 0.5 & 21 & 50 & 55 & 18 & S \\
\hline TMC 10 & 5 & 0.3 & 20 & 50 & 35 & 15 & S \\
\hline TMC 11 & 5 & 0.3 & 20 & 50 & 45 & 18 & $\mathrm{~A}$ \\
\hline TMC 12 & 5 & 0.3 & 20 & 50 & 55 & 12 & $\mathrm{H}$ \\
\hline TMC 13 & 5 & 0.4 & 21 & 30 & 35 & 15 & S \\
\hline TMC 14 & 5 & 0.4 & 21 & 30 & 45 & 18 & $\mathrm{~A}$ \\
\hline TMC 15 & 5 & 0.4 & 21 & 30 & 55 & 12 & $\mathrm{H}$ \\
\hline TMC 16 & 5 & 0.5 & 19 & 40 & 35 & 15 & $S$ \\
\hline TMC 17 & 5 & 0.5 & 19 & 40 & 45 & 18 & A \\
\hline TMC 18 & 5 & 0.5 & 19 & 40 & 55 & 12 & $\mathrm{H}$ \\
\hline TMC 19 & 6 & 0.3 & 21 & 40 & 35 & 18 & $\mathrm{H}$ \\
\hline TMC 20 & 6 & 0.3 & 21 & 40 & 45 & 12 & $S$ \\
\hline TMC 21 & 6 & 0.3 & 21 & 40 & 55 & 15 & A \\
\hline TMC 22 & 6 & 0.4 & 19 & 50 & 35 & 18 & $\mathrm{H}$ \\
\hline TMC 23 & 6 & 0.4 & 19 & 50 & 45 & 12 & $\mathrm{~S}$ \\
\hline TMC 24 & 6 & 0.4 & 19 & 50 & 55 & 15 & A \\
\hline TMC 25 & 6 & 0.5 & 20 & 30 & 35 & 18 & $\mathrm{H}$ \\
\hline TMC 26 & 6 & 0.5 & 20 & 30 & 45 & 12 & $S$ \\
\hline TMC 27 & 6 & 0.5 & 20 & 30 & 55 & 15 & $\mathrm{~A}$ \\
\hline
\end{tabular}

hours. Further, these aggregates are kept in ambient temperature conditions and were characterised at 14 , 28, and 56 days.

Solution curing (S): the APFA aggregates through the pelletization process are first allowed to set for 24 hours in ambient temperature conditions. After that, fly ash aggregates are dipped in sodium silicate solution for 30 minutes. Further, these fly ash aggregates are kept in ambient temperature conditions and were characterised at 14,28 , and 56 days.

2.7. Testing on Aggregates. The pelletization efficiency in the aggregate production is calculated using equation (1). The particle size distribution in the production was determined using standard set of sieves (IS 383-2016) [43]:

$$
\text { efficiency of pelletization }=\frac{\text { weight retained on the IS sieve no. } 480}{\text { total weight of materials used }} * 100 \text {. }
$$


The APFA aggregates were assessed for basic engineering properties such as water absorption, aggregate impact value, and aggregate crushing value as per IS 2386 [44, 45]. Crushing strength of individual pellet was estimated using a compression testing machine (ring type unconfined compression test apparatus) and crushing strength $(\sigma)$ of fly ash aggregate was calculated from the following equation [7]:

$$
\sigma=\frac{2.8 * P}{\pi * x^{2}}
$$

where $P$ represents the failure load on the pellet and $x$ is the size of pellets.

\section{Experimental Results}

Sustainable aggregates are artificially produced as explained in aggregate production section with trial runs as described in experimental program and they were evaluated for their production efficiency, particle size distribution, and engineering properties.

The experimental results were obtained at end of 14, 28, and 56 days; however, for the sake of brevity only 56 days' results are discussed in the subsequent sections.

3.1. Efficiency and the Particle Size Distribution of the Aggregate. The pelletization efficiency of the produced aggregates with respect to water content was estimated using equation (1) and it is presented in Figure 2. It can be observed from Figure 2 that the efficiency is increased from $77.96 \%$ to $96.41 \%$ as water content increased from 19 to $21 \%$.

The distribution of aggregates size in the production of fly ash aggregates with respect to different water content used is compared with nominal size of $20 \mathrm{~mm}$ graded aggregates as per IS 383-2016 [43] and presented in Figure 3. From Figure 3, it is observed that production of aggregates has a significant influence on the particle size distribution in production process. However, the APFA aggregates particle size distribution is within the limits of IS 383-2016 standards [43].

3.2. Specific Gravity and Bulk Density. The APFA aggregates which are subjected to different curing conditions were assessed for specific gravity, bulk density, and percentage of voids. The average value of apparent specific gravity, saturated surface dry specific gravity, loose and compacted bulk density of aggregates, and percentage of voids for different fly ash aggregates subjected to curing conditions are presented in Table 4.

3.3. Aggregates Impact Value. The response indices are determined from the experimental test results and the response index relationship for aggregate impact value with combined factors is presented in Figure 4. From Figure 4, it can be observed that, with increase in $\mathrm{Na}_{2} \mathrm{O}$ content from $4 \%$ to $6 \%$, aggregate impact value is improved from $27.88 \%$ to $22.78 \%$ at 56 days. Similarly increase in $\mathrm{SiO}_{2} / \mathrm{Na}_{2} \mathrm{O}$ ratio from 0.3 to 0.4 has improved the aggregate impact value from $26.71 \%$ to
$25.47 \%$, further increase of $\mathrm{SiO}_{2} / \mathrm{Na}_{2} \mathrm{O}$ ratio from 0.4 to 0.5 has marginal effect, and heat curing of artificially produced aggregates has significantly improved the aggregate impact value $23.69 \%$ when compared to aggregate impact values of $28.74 \%$ and $25.58 \%$ for ambient cured and solution cured aggregates at 56 days. The aggregate impact value gets marginally improved from $25.83 \%$ to $24.98 \%$ at 56 days with an increase in water content from $19 \%$ to $20 \%$; further increase in the water content from $20 \%$ to $21 \%$ was found to have an adversarial effect on the aggregates impact value that decreased from $24.98 \%$ to $27.21 \%$ at 56 days. It is also noted from Figure 4 that the aggregates impact value has marginally improved from $25.93 \%$ to $25.59 \%$ due to the increase in the speed of pelletizing disc from 30 RPM to 50 RPM. Further increase in the angle of pelletizing disc from $35^{\circ}$ to $55^{\circ}$ and duration of pelletization of 12 to 18 minutes has shown the negligible improve on the aggregate impact values from $26.04 \%$ to $25.96 \%$ and $26.08 \%$ to $26.25 \%$ at 56 days, respectively.

3.4. Aggregate Crushing Value. The experimental test results are used to determine the response indices and the response index relationship for aggregate crushing value with combined factors is presented in Figure 5. From Figure 5, it can be observed that, with the geopolymerisation factors such as $\mathrm{Na}_{2} \mathrm{O}$ content increase from $4 \%$ to $6 \%$, aggregate crushing value is improved from $27.21 \%$ to $23.92 \%$ at 56 days. Similarly, increase in $\mathrm{SiO}_{2} / \mathrm{Na}_{2} \mathrm{O}$ ratio from 0.3 to 0.5 has marginally improved the aggregate crushing value from $26.72 \%$ to $25.33 \%$ at 56 days. It is also observed that heat curing and solution curing of aggregates have significantly improved the aggregate crushing value of $23.37 \%$ and $25.34 \%$, respectively, at 56 days when compared to the aggregates crushing value $28.72 \%$ at 56 days of ambient cured fly ash aggregates. Aggregates crushing value has declined from $25.13 \%$ to $26.35 \%$ at 56 days due to increase in the water content in the trial mixes. However, from Figure 5, response indices of pelletization factors indicate that the duration of pelletization of 12 to 18 minutes has improved the aggregates crushing value from $26.62 \%$ to $24.17 \%$ at 56 days. Further, increase in speed of pelletizing disc from 30 RPM to 50 RPM and angle of pelletizing disc from $35^{\circ}$ to $55^{\circ}$ has negligible improvement on the aggregate crushing value from $26.01 \%$ to $25.93 \%$ and $25.93 \%$ to $25.98 \%$, respectively, at 56 days.

3.5. Crushing Strength of Individual Pellets. The response indices are calculated from the experimental test results and the response index relationship for the crushing strength of individual pellets with combined factors is presented in Figure 6. From Figure 6, it can be observed that, with the geopolymerisation factors such as the $\mathrm{Na}_{2} \mathrm{O}$ content increase from $4 \%$ to $6 \%$, crushing strength of individual pellets is improved from $3.04 \mathrm{MPa}$ to $3.79 \mathrm{MPa}$ at 56 days. Similarly, increase of $\mathrm{SiO}_{2} / \mathrm{Na}_{2} \mathrm{O}$ ratio from 0.3 to 0.5 has improved the crushing strength of individual pellets from $3.24 \mathrm{MPa}$ to $3.57 \mathrm{MPa}$ at 56 days and heat curing has significantly improved the pellets crushing strength value to $3.81 \mathrm{MPa}$ when 


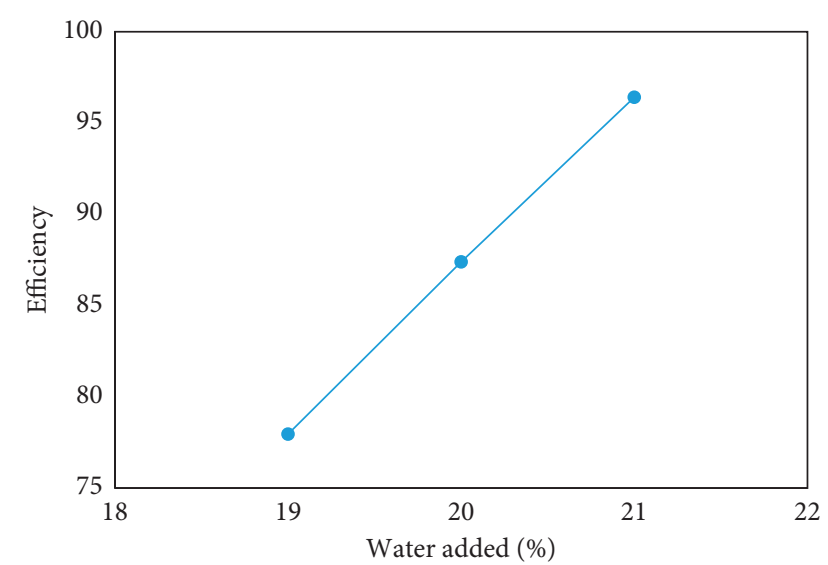

FIgure 2: Pelletization efficiency with respect to water content.

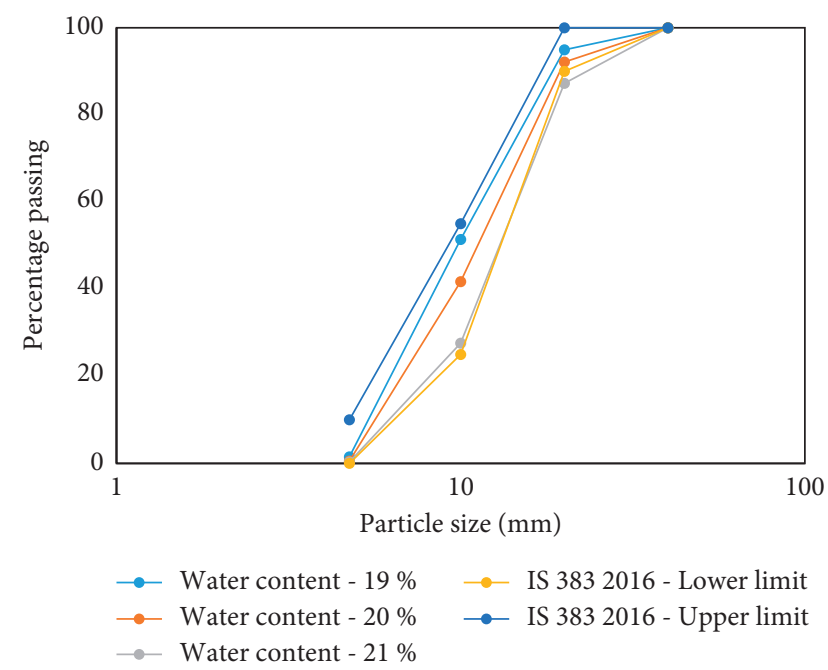

Figure 3: Particle size distribution of produced aggregates along with IS 383-2016 limits.

TABLE 4: Average specific gravity and bulk density of artificial fly ash aggregates subjected to different curing conditions.

\begin{tabular}{|c|c|c|c|c|}
\hline \multirow{2}{*}{$\begin{array}{l}\text { Curing } \\
\text { regime }\end{array}$} & \multicolumn{2}{|c|}{ Specific gravity } & \multicolumn{2}{|c|}{ Bulk density $\left(\mathrm{kg} / \mathrm{m}^{3}\right)$} \\
\hline & Apparent & $\begin{array}{c}\text { Saturated } \\
\text { surface dry }\end{array}$ & Loose & Compacted \\
\hline Ambient & 1.95 & 1.65 & 1100 & 1210 \\
\hline Heat & 1.97 & 1.62 & 1050 & 1170 \\
\hline Solution & 1.97 & 1.71 & 1110 & 1220 \\
\hline
\end{tabular}

compared to crushing strength of individual pellets values 3.08 $\mathrm{MPa}$ and 3.28 MPa of ambient cured and solution cured aggregates at 56 days. Aggregate crushing strength of individual pellets has declined from $3.50 \mathrm{MPa}$ to $3.21 \mathrm{MPa}$ at 56 days with increase in the water content from $19 \%$ to $21 \%$. It can be also understood from Figure 6 that pelletization factors response indices indicate a trivial improvement in pellets crushing strength from 3.36 MPa to 3.49 MPa due to the increase in the duration of pelletization from 12 to 18 minutes. However, increase in the angle of pelletizing disc from $35^{\circ}$ to $55^{\circ}$ and speed of pelletizing disc from 30 RPM to
50 RPM has shown the negligible improvement on the pellets crushing strength from $3.38 \mathrm{MPa}$ to $3.39 \mathrm{MPa}$ and 3.39 $\mathrm{MPa}$ to $3.41 \mathrm{MPa}$, respectively, at 56 days.

3.6. Water Absorption. The experimental test results are used to determine the response indices and the response index relationship for water absorption with combined factors is presented in Figure 7. From Figure 7, it is found that, with geopolymerisation factors such as $\mathrm{Na}_{2} \mathrm{O}$ content from $4 \%$ to $6 \%$, water absorption value improved from $11.37 \%$ to $9.04 \%$ and with increase in $\mathrm{SiO}_{2} / \mathrm{Na}_{2} \mathrm{O}$ ratio from 0.3 to 0.5 the water absorption also reduced from $10.91 \%$ to $9.92 \%$ at 56 days. It is also observed that solution curing of artificially produced aggregates has significantly reduced the water absorption value to $8.42 \%$ when compared to water absorption values of $10.58 \%$ and $12.44 \%$ for ambient cured and heat cured aggregates at 56 days. However, increase in speed of pelletizing disc from 30 RPM to 50 RPM and change in the angle of pelletizing disc from $35^{\circ}$ to $55^{\circ}$ have improved the water absorption of aggregates marginally from $10.47 \%$ to $9.82 \%$ and $10.76 \%$ to $10.26 \%$, respectively, at 56 days. It is observed that duration of pelletization of 12 to 18 minutes has the water absorption values of $10.42 \%$ to $10.68 \%$ which has negligible effect on water absorption of aggregates.

\section{Grey Relational Analysis}

Sahoo et al. have presented the advantages of grey relational analysis in categorizing the most influencing parameters with respect to the material properties [46]. In this investigation, experimental test results on the APFA aggregates were considered as responses and grey relational analysis was carried out as follows.

4.1. Determination of Grey Relational Generations. The aggregate properties results such as aggregate impact value, aggregate crushing value, crushing strength of individual pellets, and water absorption are considered as responses for the grey relational analysis. In this analysis, standardization of responses is carried out such that the lower the obtained value for the produced aggregates the better for aggregate impact value, aggregate crushing value, and water absorption, whereas the higher value obtained is better for crushing strength of individual pellets of APFA aggregates. Grey relational generation was obtained with the experimental values to scale of $0-1$ and it was calculated using equation (3). Computed grey relational generations on the responses are presented in Tables 5-7 at different curing ages.

$$
x_{i}=\frac{\max y_{i}(k)-y_{i}(k)}{\max y_{i}(k)-\min y_{i}(k)},
$$

where $x_{i}(k)=$ value after the GRG; $\min y_{i}(k)=$ smallest value of $y_{i}(k)$ for the $k^{\text {th }}$ response; and $\max y_{i}(k)=$ largest value of $y_{i}(k)$ for the $k^{\text {th }}$ response.

4.2. Assessment of Grey Relational Coefficients and Grey Relational Grades. The assessment of Grey relational 

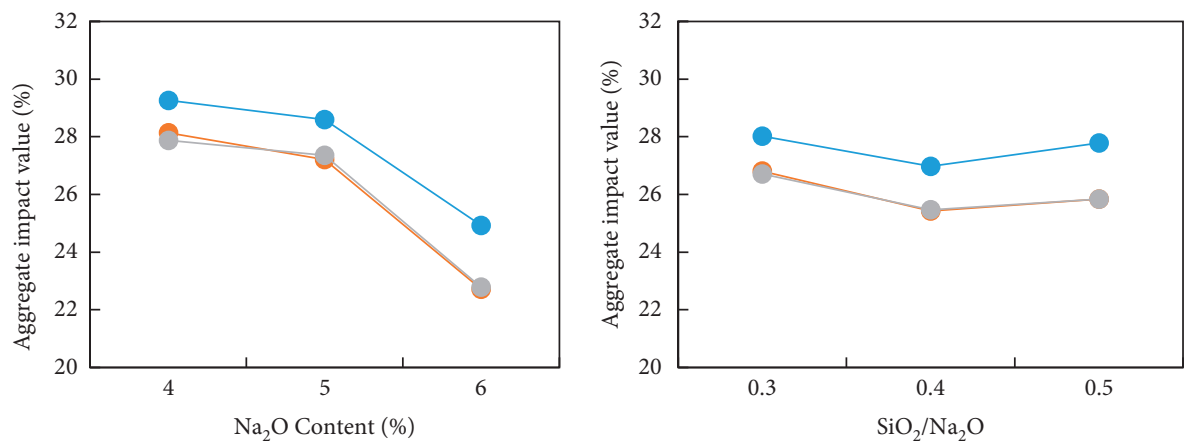

-14 days
-28 days

- 14 days

- 56 days

- 28 days
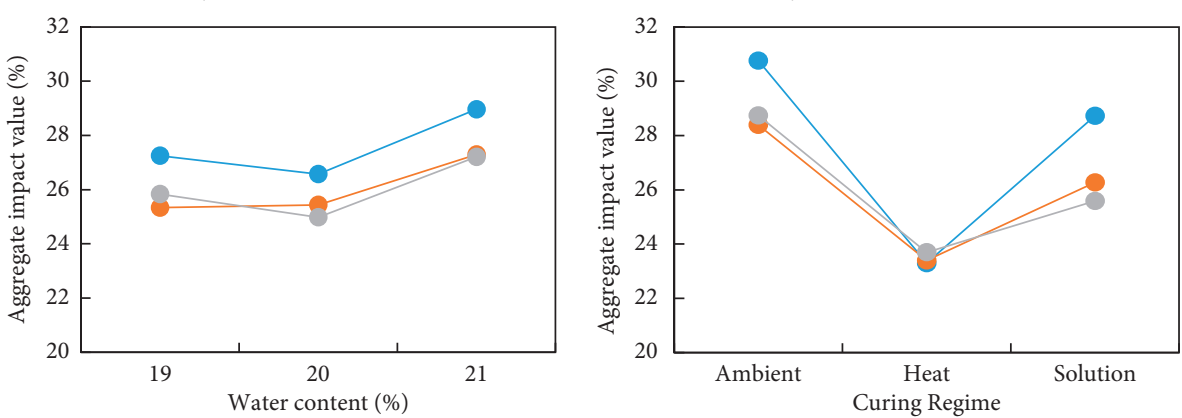

- 14 days

- 14 days

- 28 days

- 28 days

- 56 days

- 56 days
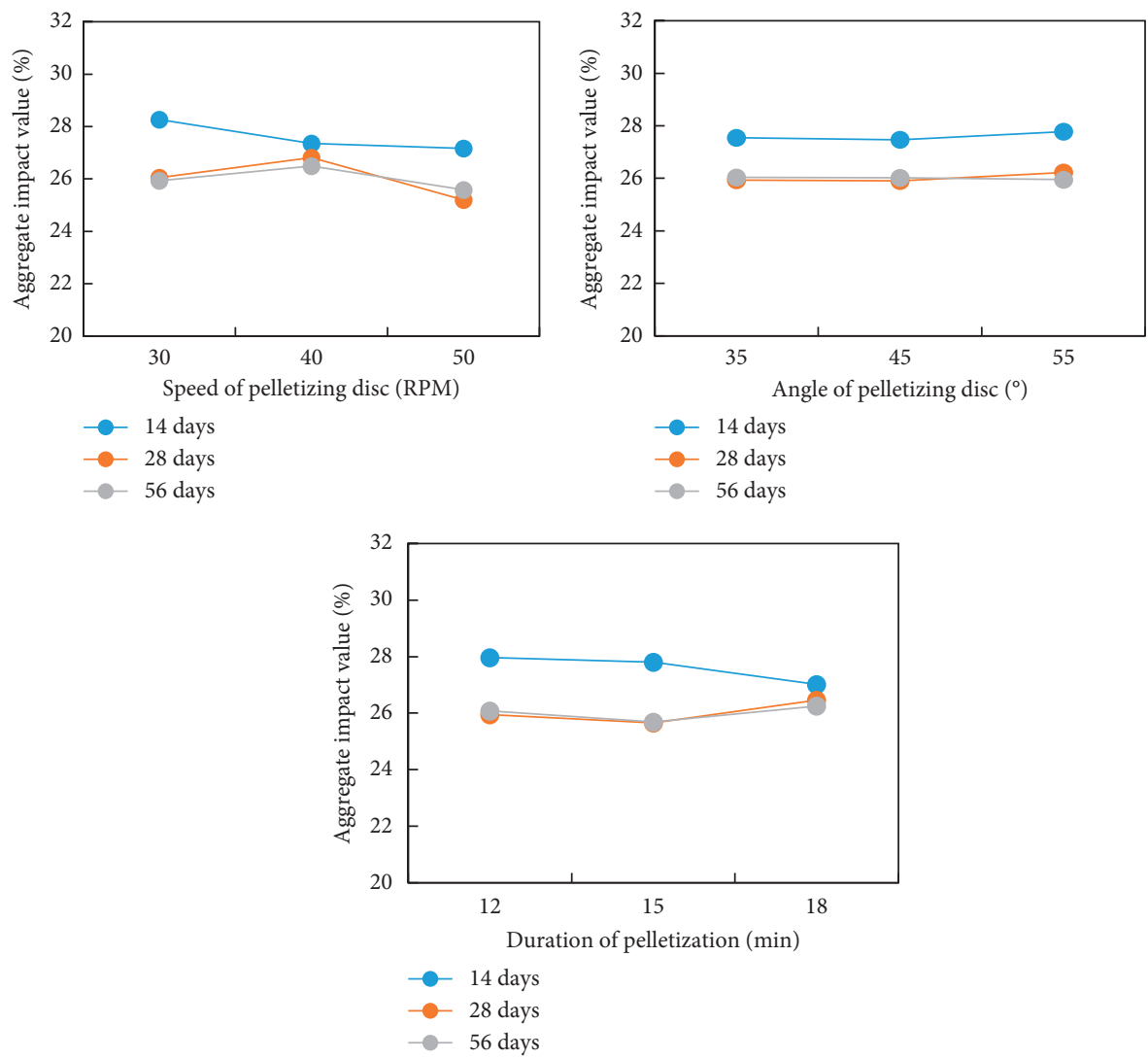

FIgURE 4: Response index relationship for aggregate impact value with combined factors. 

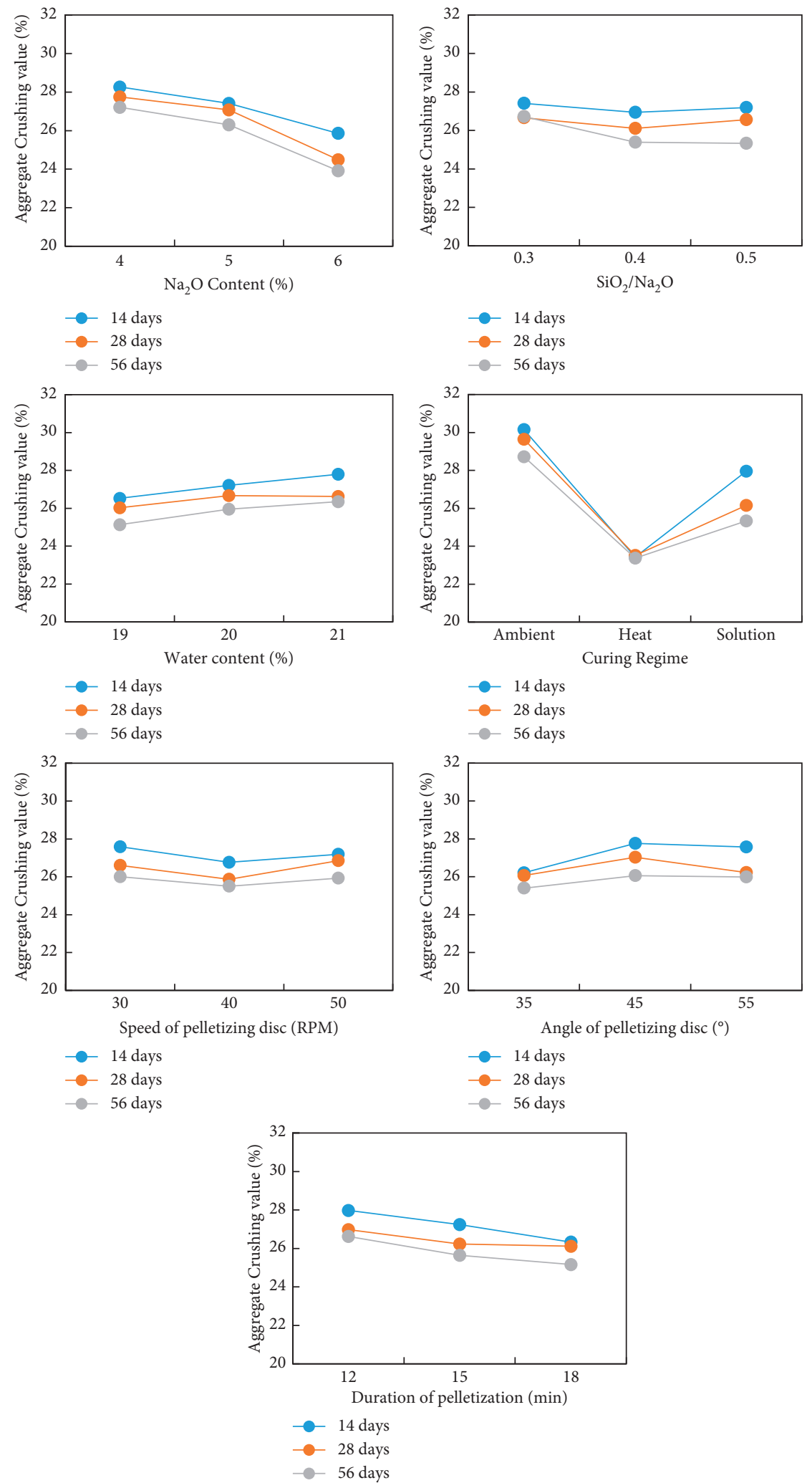

Figure 5: Response index relationship for aggregate crushing value with combined factors. 

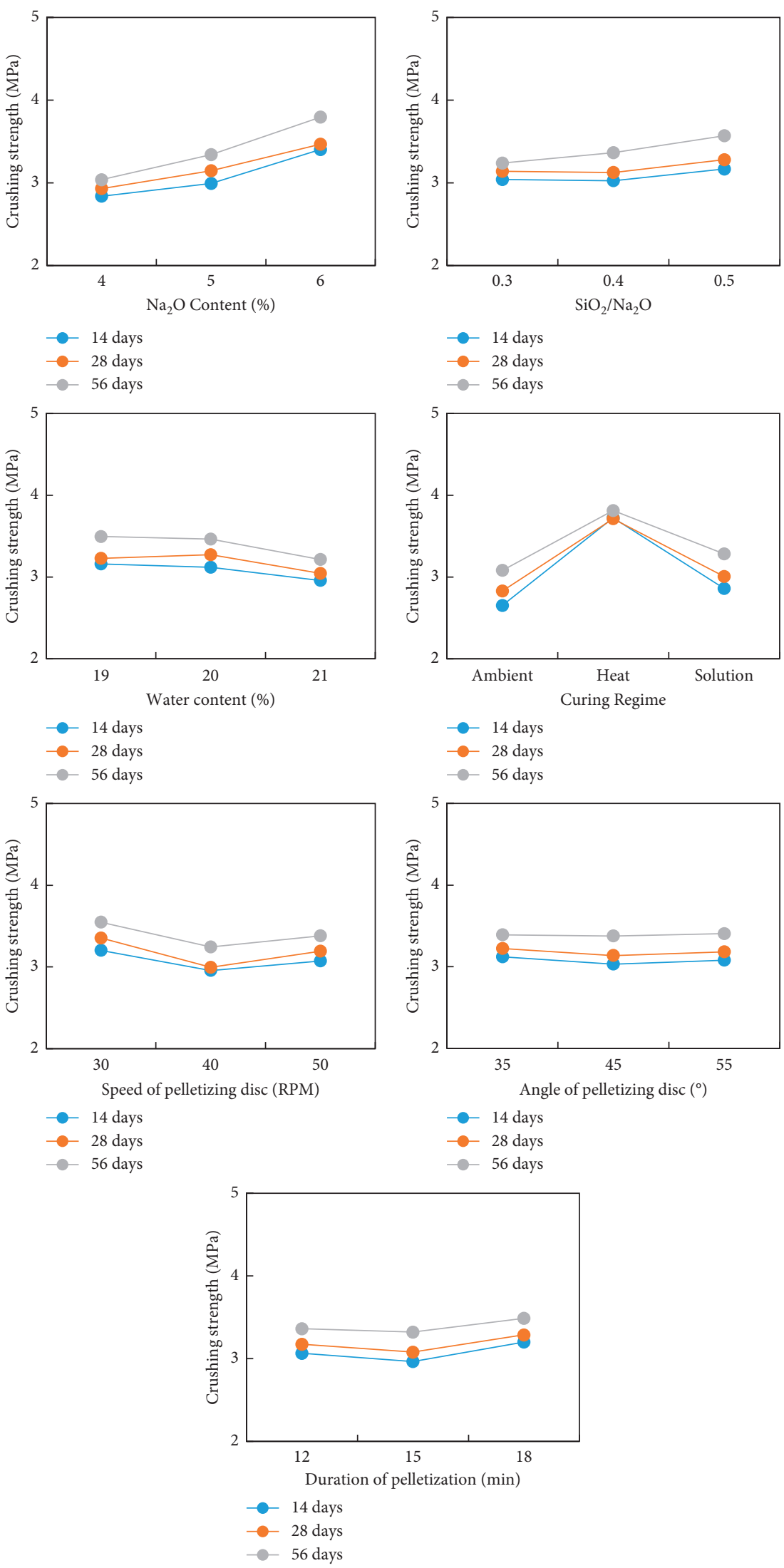

FIGURE 6: Response index relationship for crushing strength of individual pellets with combined factors. 

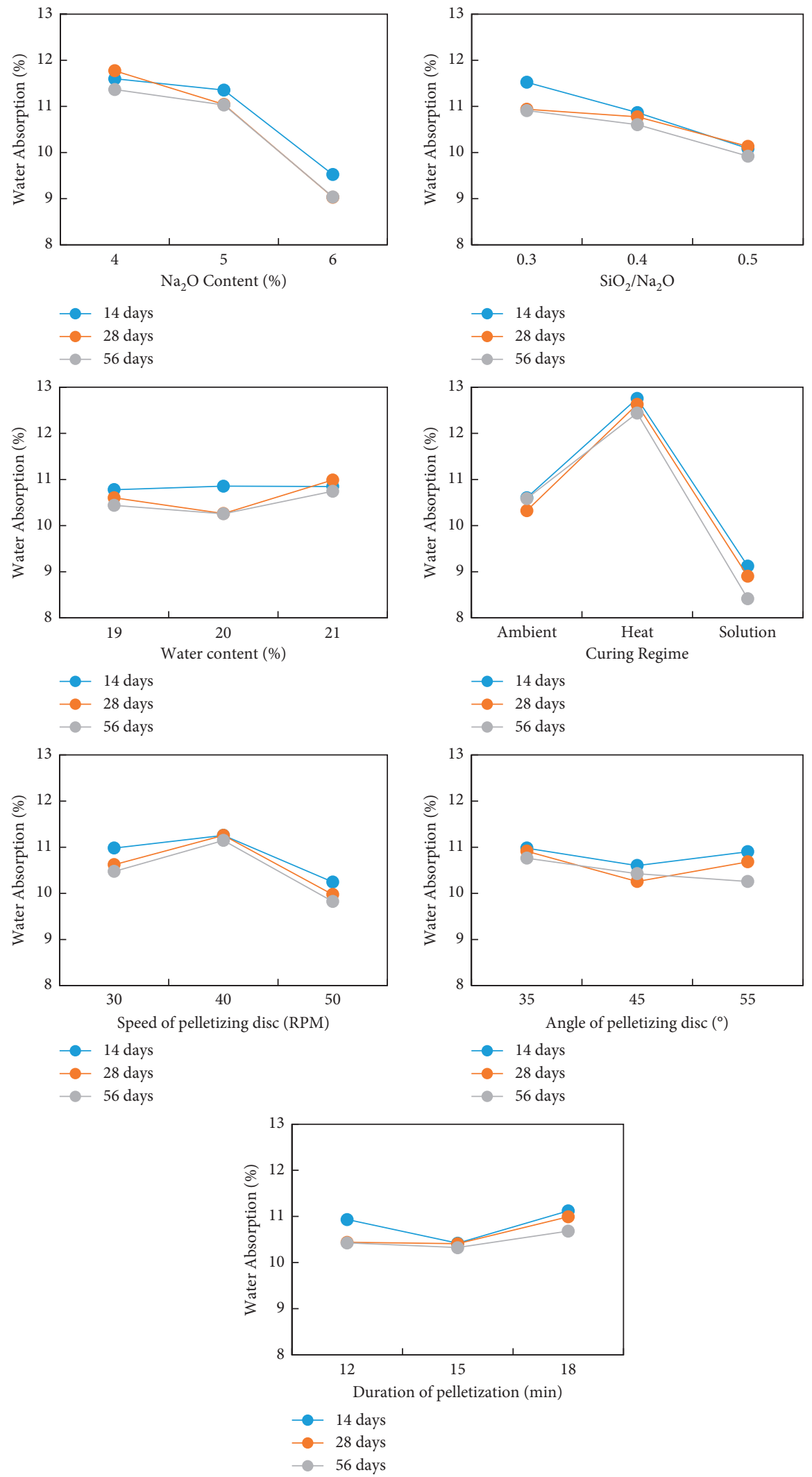

FIGURE 7: Response index relationship for water absorption with combined factors. 


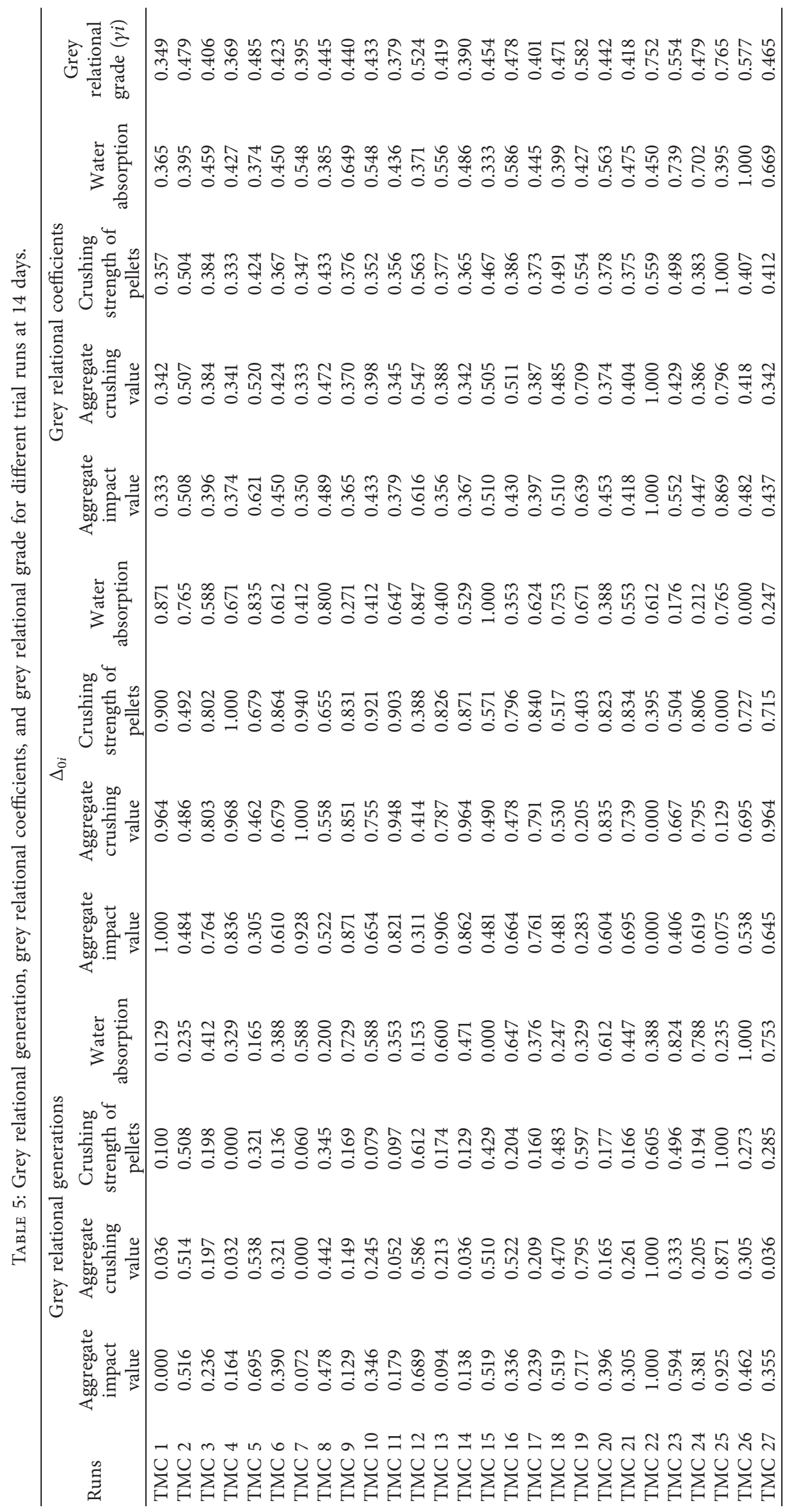




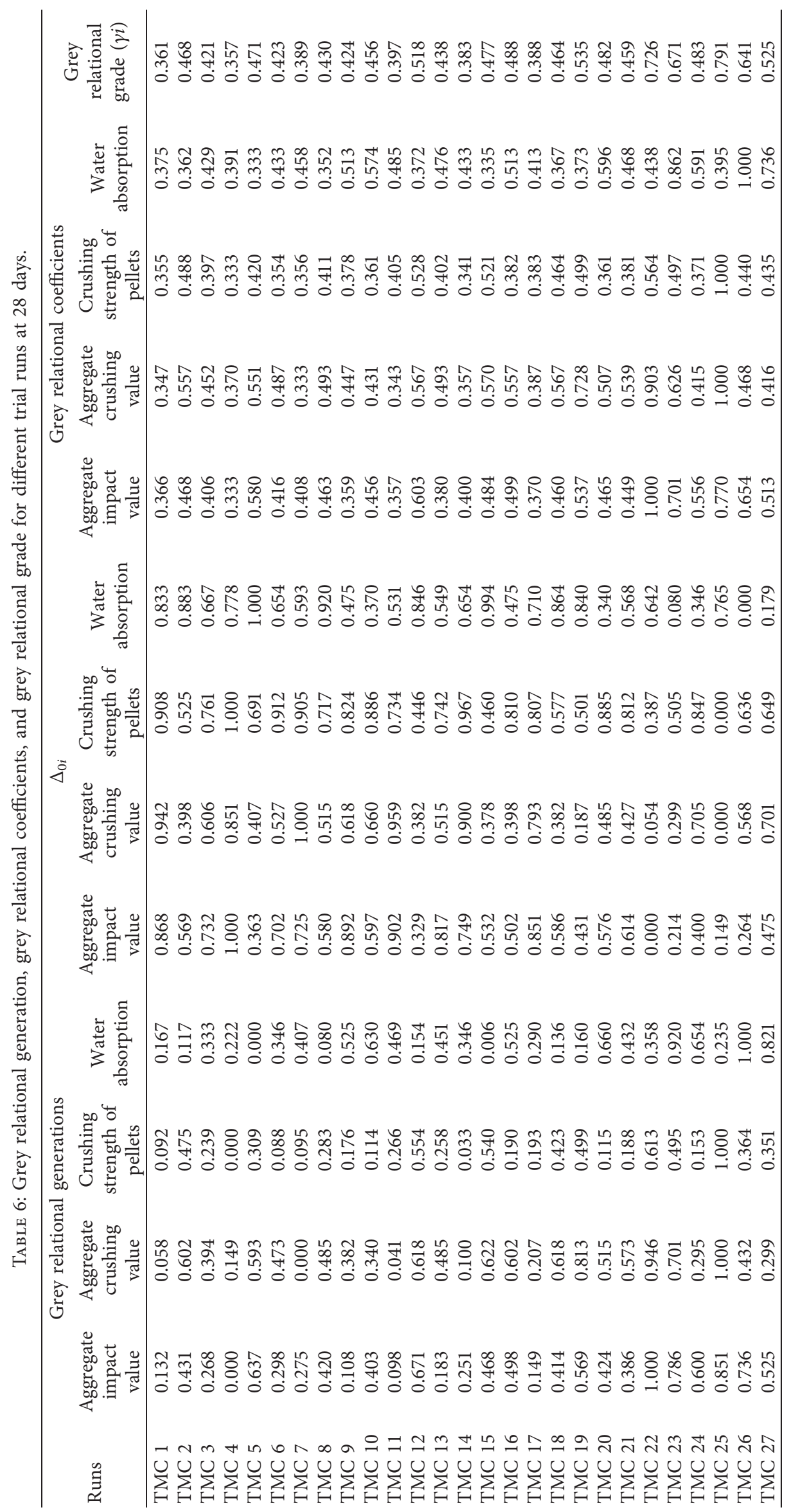




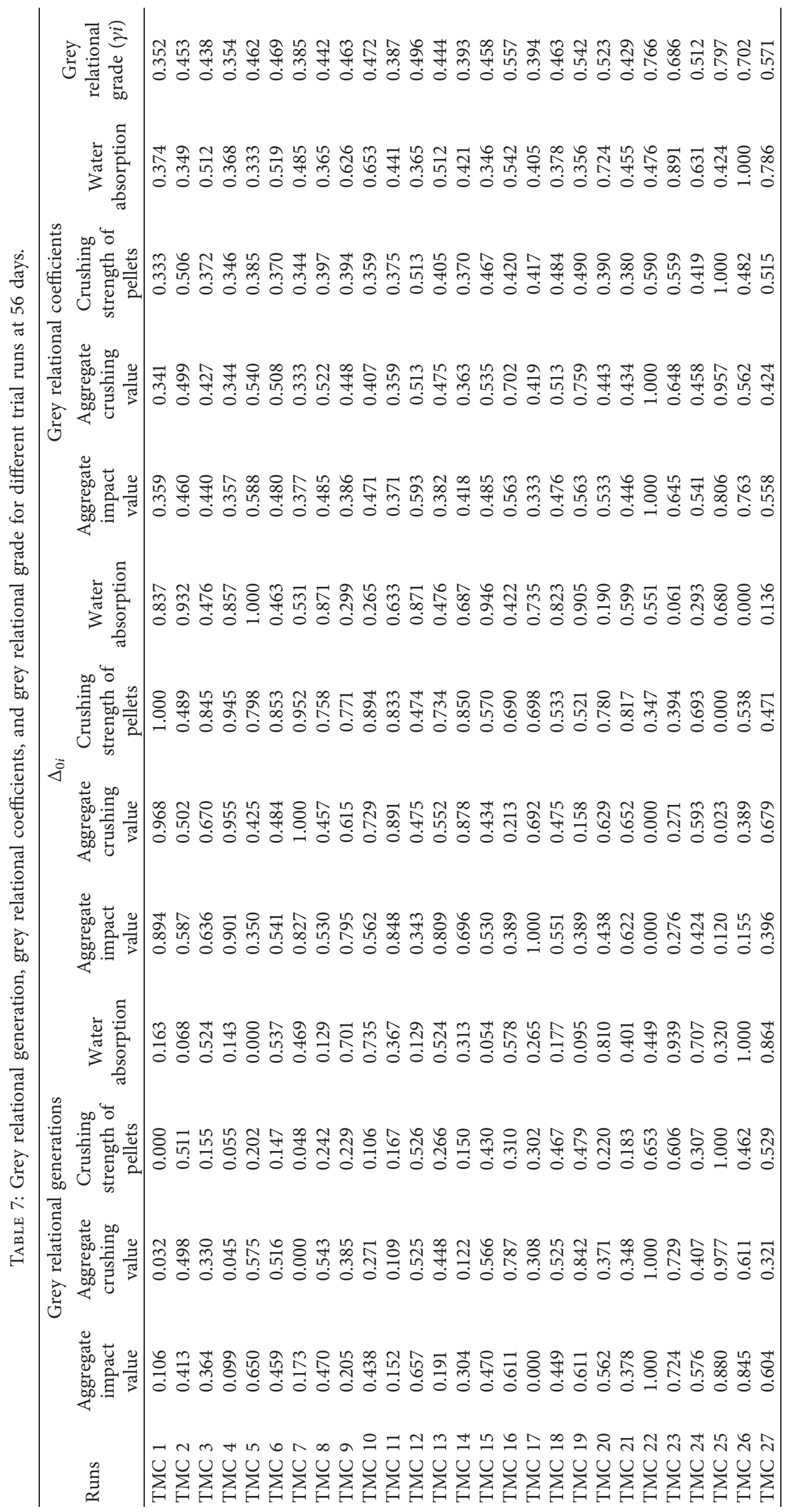


TABLE 8: Grey relational grade with respect to combined factors at various ages.

\begin{tabular}{|c|c|c|c|c|c|c|}
\hline \multirow{2}{*}{ Factor } & \multirow{2}{*}{ Curing ages } & \multicolumn{3}{|c|}{ Grey relational grade } & \multirow{2}{*}{ Maximum value-minimum value } & \multirow{2}{*}{ Rank } \\
\hline & & Level 1 & Level 2 & Level 3 & & \\
\hline $\mathrm{Na}_{2} \mathrm{O}$ content $(\%)$ & & 0.421 & 0.439 & 0.559 & 0.138 & 2 \\
\hline $\mathrm{SiO}_{2} / \mathrm{Na}_{2} \mathrm{O}$ ratio & & 0.446 & 0.481 & 0.493 & 0.047 & 6 \\
\hline Water content $(\%)$ & & 0.486 & 0.491 & 0.443 & 0.048 & 4 \\
\hline Speed of pelletizing disc (RPM) & 14 days & 0.478 & 0.452 & 0.489 & 0.037 & 7 \\
\hline Angle of pelletizing disc $\left({ }^{\circ}\right)$ & & 0.505 & 0.461 & 0.453 & 0.051 & 3 \\
\hline Duration of pelletization (min) & & 0.460 & 0.456 & 0.504 & 0.048 & 4 \\
\hline Curing regime & & 0.405 & 0.551 & 0.464 & 0.146 & 1 \\
\hline $\mathrm{Na}_{2} \mathrm{O}$ content $(\%)$ & & 0.416 & 0.445 & 0.590 & 0.175 & 1 \\
\hline $\mathrm{SiO}_{2} / \mathrm{Na}_{2} \mathrm{O}$ ratio & & 0.455 & 0.492 & 0.504 & 0.049 & 4 \\
\hline Water content $(\%)$ & & 0.497 & 0.509 & 0.446 & 0.062 & 3 \\
\hline Speed of pelletizing disc (RPM) & 28 days & 0.501 & 0.452 & 0.499 & 0.049 & 4 \\
\hline Angle of pelletizing disc $\left(^{\circ}\right)$ & & 0.504 & 0.481 & 0.466 & 0.038 & 6 \\
\hline Duration of pelletization (min) & & 0.484 & 0.469 & 0.499 & 0.030 & 7 \\
\hline Curing regime & & 0.416 & 0.542 & 0.494 & 0.126 & 2 \\
\hline $\mathrm{Na}_{2} \mathrm{O}$ content $(\%)$ & & 0.424 & 0.451 & 0.614 & 0.190 & 1 \\
\hline $\mathrm{SiO}_{2} / \mathrm{Na}_{2} \mathrm{O}$ ratio & & 0.455 & 0.505 & 0.530 & 0.076 & 3 \\
\hline Water content $(\%)$ & & 0.513 & 0.523 & 0.453 & 0.070 & 4 \\
\hline Speed of pelletizing disc (RPM) & 56 days & 0.512 & 0.466 & 0.512 & 0.047 & 5 \\
\hline Angle of pelletizing disc $\left({ }^{\circ}\right)$ & & 0.519 & 0.493 & 0.478 & 0.041 & 6 \\
\hline Duration of pelletization (min) & & 0.491 & 0.482 & 0.517 & 0.034 & 7 \\
\hline Curing regime & & 0.420 & 0.542 & 0.528 & 0.123 & 2 \\
\hline
\end{tabular}

coefficients (GRC) plays a vital role in grey relational analysis, which correlates the desired and actual obtained results. The GRC was calculated by using equation (4) and computed GRC are presented in Tables 5-7 with respect to different trial runs at different curing ages.

$$
\xi_{i}(k)=\frac{\Delta_{\min }+\psi \Delta_{\max }}{\Delta_{0 i}(k)+\psi \Delta_{\max }},
$$

where $\Delta_{0 i}=\left\|x_{0}(k)-x_{i}(k)\right\|$ is the difference of the absolute value between $x_{0}(k)$ and $x_{i}(k)$ and $\Delta_{\max }$ and $\Delta_{\text {min }}=$ maximum and minimum values of the absolute differences of all comparing sequences, respectively. $\psi$ is a distinguishing coefficient $(0 \leq \psi \leq 1)$ and in the present study, $\psi=0.5$ is taken.

The Grey relational grade (GRG) $\gamma_{i}$ is calculated using equation (5) and presented in Tables 5-7 at various curing ages. If the Grey relational grade is higher it signifies a stronger relational degree between the investigated trial run and the ideal sequence.

$$
\gamma_{i}=\frac{1}{n} \sum_{k=1}^{n} A P(k) \xi_{i}(k),
$$

where $n=$ number of process responses.

The GRG was computed for individual factors with respect to combined factors and the values of GRG are presented in Table 8. From Table 8, it is observed that the highest GRG among the geopolymerisation factors is $6 \%$ of $\mathrm{Na}_{2} \mathrm{O}$ content (level 3) followed by curing regime-heat curing (level 2) and 0.5 of $\mathrm{SiO}_{2} / \mathrm{Na}_{2} \mathrm{O}$ ratio (level 3) and among the pelletization factors the highest GRG is observed for angle of pelletization disc (level 1) and followed by 18 minutes of duration of pelletization (level 3 ) and speed of pelletization disc at 50 RPM (level 3). Whereas water content is the important factor which plays important role in geopolymerisation and pelletization process, it is observed that higher GRG is observed for $20 \%$ of water content (level 2).

The level of significance of each individual factor is estimated through difference of maximum and minimum values. It is ranked according to the higher differences in the values of Grey relational grade and is presented in Table 8. From the table, based on the rank given in the grey relational analysis for the geopolymerisation factors, it clearly indicates that the curing regime and higher $\mathrm{Na}_{2} \mathrm{O}$ content have major role in the aggregates production at early ages. However, the higher $\mathrm{Na}_{2} \mathrm{O}$ content plays significant role in improving the engineering properties of the produced aggregates. Further, it is observed that curing regime rank is changed since solution curing of produced aggregates has improved overall engineering properties of aggregates at later ages. It is clear that, in the fly ash aggregate production with alkaline solution, $\mathrm{Na}_{2} \mathrm{O}$ content, curing regime, and $\mathrm{SiO}_{2} / \mathrm{Na}_{2} \mathrm{O}$ ratio play major role in the rate of geopolymerisation of fly ash. Further, the GRG for factors of pelletization such as speed of pelletizing disc, angle of pelletizing disc, and duration of pelletization has relatively less influence as compared to the factors of geopolymerisation such as $\mathrm{Na}_{2} \mathrm{O}$ content, $\mathrm{SiO}_{2} / \mathrm{Na}_{2} \mathrm{O}$ ratio, water content, and curing regime in the production of artificial aggregates. However, water content plays a prominent and dual role in geopolymerisation process and pelletization which acts as a medium in the process.

\section{Discussion}

The response indices of individual properties of aggregates from Figures 4 to 7 and combined effect in the grey relational analysis from Table 8 clearly show that higher $\mathrm{Na}_{2} \mathrm{O}$ content, higher $\mathrm{SiO}_{2} / \mathrm{Na}_{2} \mathrm{O}$ ratio, and heat curing have significant 
influence on the properties of APFA aggregates due to higher rate of geopolymerisation $[15,24]$. Whereas the heat curing of aggregates increased the water absorption in the aggregates, solution curing has significantly improved water absorption in the aggregates which can be observed in the response indices in Figure 7, which corresponds to the higher degree of geopolymerisation of fly ash particles on the surface of the aggregates $[10,15,24]$. On the other hand, response indices of individual aggregates properties with different pelletization factors observed in Figures 4 to 7 and grey relational analysis from Table 8 clearly showed that the influence of the pelletization factors on the aggregate properties is negligible.

Further, it is observed that water content played an important role in the production process and to attain the necessary engineering properties of APFA aggregates due to following reasons. Firstly, in production stage, as the water content increases from $19 \%$ to $21 \%$, the efficiency of production improved and particle size distribution of produced aggregates has marginally shifted towards coarser side. It is also observed from response indices of individual properties of aggregates from Figures 4 to 7 and combined effect in the grey relational analysis from Table 8 that an increase in water content from $19 \%$ to $21 \%$ has marginal and adverse effect on the properties of the APFA aggregates. In the geopolymerisation process of APFA aggregates, this water content may be used in early surface hydrolysis of fly ash particles or insufficient water for surface hydrolysis of fly ash which lead to less contribution to mechanical strength $[17,47,48]$.

\section{Conclusions}

From this experimental study, it can be concluded that water content in alkaline solution plays a major role in the production process of the artificial aggregates and also to their engineering properties. Water content of $20 \%$ by mass of fly ash was found to be essential for the suitable production of artificial aggregates. It is observed that engineering properties of produced aggregates are very much sensitive to the factors of the geopolymerisation such as $\mathrm{Na}_{2} \mathrm{O}$ content, $\mathrm{SiO}_{2} / \mathrm{Na}_{2} \mathrm{O}$ ratio, and curing regime. The most vital factors such as $\mathrm{Na}_{2} \mathrm{O}$ content and heat curing improved the engineering properties at an early age attributed to the faster rate of degree of polymerisation. However, solution curing of produced aggregates has improved overall engineering properties of aggregates at later ages due to continuous geopolymerisation process, since the aggregates have absorbed sodium silicate solution during the curing period and that contributes to engineering properties at later ages. Further, statistically designed experiments showed that geopolymerisation factors have significantly influenced the engineering properties of the APFA aggregates as compared to the pelletization factors.

\section{Data Availability}

The experimental data used to support the findings of this study are included within the article.

\section{Conflicts of Interest}

The authors declare that there are no conflicts of interest.

\section{Authors' Contributions}

The manuscript has been read and approved by all authors.

\section{References}

[1] A. Hasanbeigi, L. Price, and E. Lin, "Emerging energy-efficiency and $\mathrm{CO} 2$ emission-reduction technologies for cement and concrete production: a technical review," Renewable and Sustainable Energy Reviews, vol. 16, no. 8, pp. 6220-6238, 2012.

[2] P. K. Mehta, "Greening of the concrete industry for sustainable development," Concrete International, vol. 24, no. 7, pp. 23-28, 2002.

[3] Freedonia, World Construction Aggregates - Industry Study with Forecasts for 2019 and 2024, The Freedonia Group, Cleveland, OH, USA, 2019.

[4] G. Baykal and A. G. Döven, "Utilization of fly ash by pelletization process; theory, application areas and research results," Resources, Conservation and Recycling, vol. 30, no. 1, pp. 59-77, 2000.

[5] J. L. Clarke, Structural Lightweight Aggregate concrete, pp. 7-12, CRC Press; Taylor \& Francis Group, Boca Raton, FL, US, 2014 Apr 21.

[6] C. Gunasekara, S. Setunge, D. W. Law, N. Willis, and T. Burt, "Engineering properties of geopolymer aggregate concrete," Journal of Materials in Civil Engineering, vol. 30, no. 11, Article ID 04018299, 2018 Aug 30.

[7] P. Gomathi and A. Sivakumar, "Characterization on the strength properties of pelletized fly ash aggregate," ARPN Journal of Engineering and Applied Sciences, vol. 7, no. 11, pp. 1523-1532, 2012.

[8] P. Priyadharshini, G. Mohan Ganesh, and A. S. Santhi, "Experimental study on cold bonded fly ash aggregates," International Journal of Civil and Structural Engineering, vol. 2, no. 2, pp. 493-501, 2011.

[9] K. Ramamurthy and K. I. Harikrishnan, "Influence of binders on properties of sintered fly ash aggregate," Cement and Concrete Composites, vol. 28, no. 1, pp. 33-38, 2006.

[10] M. Gesoglu, T. Ozturan, and E. Guneyisi, "Effects of fly ash properties on characteristics of cold-bonded fly ash lightweight aggregates," Construction and Building Materials, vol. 21, no. 9, pp. 1869-1878, 2007.

[11] K. I. Harikrishnan and K. Ramamurthy, "Influence of pelletization process on the properties of fly ash aggregates," Waste Management, vol. 26, no. 8, pp. 846-852, 2006.

[12] P. Gomathi and A. Sivakumar, "Fly ash based lightweight aggregates incorporating clay binders," Indian Journal of Engineering and Materials Sciences, vol. 21, no. 2, pp. 227-232, 2014.

[13] N. U. Kockal and T. Ozturan, "Characteristics of lightweight fly ash aggregates produced with different binders and heat treatments," Cement and Concrete Composites, vol. 33, no. 1, pp. 61-67, 2011.

[14] R. Manikandan and K. Ramamurthy, "Effect of curing method on characteristics of cold bonded fly ash aggregates," Cement and Concrete Composites, vol. 30, no. 9, pp. 848-853, 2008.

[15] B. V. Rangan, D. Hardjito, E. W. Steenie, and M. J. S. Dody, "Studies on fly ash-based geopolymer concrete," Proceedings 
of the World Congress Geopolymer, Saint Quentin, France, vol. 28, pp. 133-137, 2005.

[16] J. Davidovits, "Geopolymers and geopolymeric materials," Journal of Thermal Analysis, vol. 35, no. 2, pp. 429-441, 1989.

[17] D. Khale and R. Chaudhary, "Mechanism of geopolymerization and factors influencing its development: a review," Journal of Materials Science, vol. 42, no. 3, pp. 729-746, 2007.

[18] M. Komljenovic, Z. Bascarevic, and V. Bradic, "Mechanical and microstructural properties of alkali-activated fly ash geopolymers," Journal of Hazardous Materials, vol. 181, no. 1, pp. 35-42, 2010.

[19] H. Y. Leong, D. E. L. Ong, J. G. Sanjayan, and A. Nazari, “The effect of different $\mathrm{Na} 2 \mathrm{O}$ and $\mathrm{K} 2 \mathrm{O}$ ratios of alkali activator on compressive strength of fly ash based-geopolymer," Construction and Building Materials, vol. 106, pp. 500-511, 2016 Mar 1.

[20] D. Hardjito, C. C. Chua, and H. L. Carrie, "Strength and setting times of low calcium fly ash-based geopolymer mortar," Modern Applied Science, vol. 2, no. 4, pp. 3-5, 2008.

[21] U. Rattanasak and P. Chindaprasirt, "Influence of $\mathrm{NaOH}$ solution on the synthesis of fly ash geopolymer," Minerals Engineering, vol. 22, no. 12, pp. 1073-1078, 2009.

[22] A. M. Mustafa Al Bakri, H. Kamarudin, M. Bnhussain, A. R. Rafiza, and Y. Zarina, "Effect of $\mathrm{Na}_{2} \mathrm{SiO}_{3} / \mathrm{NaOH}$ ratios and $\mathrm{NaOH}$ molarities on compressive strength of fly-ashbased geopolymer," ACI Materials Journal, vol. 109, no. 5, pp. 503-508, 2012.

[23] G. Görhan and G. Kürklü, "The influence of the $\mathrm{NaOH}$ solution on the properties of the fly ash-based geopolymer mortar cured at different temperatures," Composites Part B: Engineering, vol. 58, pp. 371-377, 2014.

[24] S. V. Patankar, Y. M. Ghugal, and S. S. Jamkar, "Effect of concentration of sodium hydroxide and degree of heat curing on fly ash-based geopolymer mortar," Indian Journal of Materials Science, vol. 2014, Article ID 938789, 6 pages, 2014.

[25] D. Hardjito, E. W. Steenie, M. J. S. Dody, and B. V. Rangan, "On the development of fly ash-based geopolymer concrete," ACI Materials Journal - American Concrete Institute, vol. 101, no. 6, pp. 467-472, 2004.

[26] A. Fernández-Jiménez and A. Palomo, "Composition and microstructure of alkali activated fly ash binder: effect of the activator," Cement and Concrete Research, vol. 35, no. 10, pp. 1984-1992, 2005.

[27] T. Rahmiati, K. A. Azizli, Z. Man, L. Ismail, and M. F. Nuruddin, "Effect of solid/liquid ratio during curing time fly ash based geopolymer on mechanical property," Materials Science Forum, vol. 803, pp. 120-124, 2014.

[28] D. L. Y. Kong, J. G. Sanjayan, and K. Sagoe-Crentsil, "Comparative performance of geopolymers made with metakaolin and fly ash after exposure to elevated temperatures," Cement and Concrete Research, vol. 37, no. 12, pp. 1583-1589, 2007.

[29] M. Cavazzuti, "Design of experiments," in Optimization Methods, pp. 13-42, Springer Berlin Heidelberg, Heidelberg, German, 2013.

[30] T. Krishnan and R. Purushothaman, "Optimization and influence of parameter affecting the compressive strength of geopolymer concrete containing recycled concrete aggregate: using full factorial design approach," IOP Conference Series: Earth and Environmental Science, vol. 80, no. 1, Article ID 012013, 2017 Jul.

[31] M. A. Mosaberpanah and O. Eren, " $\mathrm{CO}_{2}-$ full factorial optimization of an ultra-high-performance concrete mix design,"
European Journal of Environmental and Civil Engineering, vol. 22, pp. 1-4, 2016 Jul 20.

[32] M. Sonebi, L. Svermova, and P. J. Bartos, "Factorial design of cement slurries containing limestone powder for self-consolidating slurry-infiltrated fiber concrete," Materials Journal, vol. 101, no. 2, pp. 136-145, 2004.

[33] K. A. Soudki, E. F. El-Salakawy, and N. B. Elkum, "Full factorial optimization of concrete mix design for hot climates," Journal of Materials in Civil Engineering, vol. 13, no. 6, pp. 427-433, 2001 Dec.

[34] N. U. Kockal and T. Ozturan, "Effects of lightweight fly ash aggregate properties on the behavior of lightweight concretes," Journal of Hazardous Materials, vol. 179, no. 1-3, pp. 954-965, 2010 Jul 15.

[35] G. Hanrahan and K. Lu, "Application of factorial and response surface methodology in modern experimental design and optimization," Critical Reviews in Analytical Chemistry, vol. 36, no. 3-4, pp. 141-151, 2006 Dec 1.

[36] V. Vasugi and K. Ramamurthy, "Identification of design parameters influencing manufacture and properties of coldbonded pond ash aggregate," Materials and Design, vol. 54, pp. 264-278, 2014 Feb 1.

[37] M. Olivia and H. Nikraz, "Properties of fly ash geopolymer concrete designed by Taguchi method," Materials and Design, vol. 36, pp. 191-198, 2012 Apr 1.

[38] L. Srinivasan, K. Mohammad Chand, T. Deepan Bharathi Kannan, P. Sathiya, and S. Biju, "Application of GRA and TOPSIS optimization techniques in GTA welding of 15CDV6 aerospace material," Transactions of the Indian Institute of Metals, vol. 71, no. 2, pp. 373-382, 2018 Feb 1.

[39] Bureau of Indian Standards, IS 3812 - Part 1, Specification for Pulverized Fuel Ash: For Use as Pozzolana in Cement, Cement Mortar and concrete, Bureau of Indian Standards, New Delhi, 2013.

[40] A. Wongsa, Y. Zaetang, V. Sata, and P. Chindaprasirt, "Properties of lightweight fly ash geopolymer concrete containing bottom ash as aggregates," Construction and Building Materials, vol. 111, pp. 637-643, 2016 May 15.

[41] K. N. Shivaprasad and B. B. Das, "Influence of alkali binder dosage on the efficiency of pelletization of aggregates from iron ore tailing and fly ash," International Journal of Engineering Research in Mechanical and Civil Engineering, vol. 2, no. 3, pp. 388-392, 2017.

[42] K. N. Shivaprasad and B. B. Das, "Effect of duration of heat curing on the artificially produced fly ash aggregates," in IOP Conference Series: Materials Science and Engineeringvol. 431, no. 9, IOP Publishing, Article ID 092013, 2018 October.

[43] Bureau of Indian Standards, IS 383, Coarse and fine Aggregates for concrete - Specification, Bureau of Indian Standards, New Delhi, 2016.

[44] Bureau of Indian Standards, IS 2386 - Part 3, Methods of Test for Aggregates for concrete: Specific Gravity, Density, Voids, Absorption and Bulking, Bureau of Indian Standards, New Delhi, 1963.

[45] Bureau of Indian Standards, IS 2386 - Part 4, Methods of Test for Aggregates for concrete, Mechanical properties Bureau of Indian Standards, New Delhi, 1963.

[46] S. Sahoo, B. B. Das, and S. Mustakim, "Acid, alkali, and chloride resistance of concrete composed of low-carbonated fly ash," Journal of Materials in Civil Engineering, vol. 29, no. 3, pp. 1-12, Article ID 04016242, 2016.

[47] B. Joseph and G. Mathew, "Influence of aggregate content on the behavior of fly ash based geopolymer concrete," Scientia Iranica, vol. 19, no. 5, pp. 1188-1194, 2012 Oct 1. 
[48] L. Weng and K. Sagoe-Crentsil, "Dissolution processes, hydrolysis and condensation reactions during geopolymer synthesis: Part I-Low Si/Al ratio systems," Journal of Materials Science, vol. 42, no. 9, pp. 2997-3006, 2007 May 1. 